\title{
Mucocutaneous lesions associated with SARS-CoV-2 infection (Review)
}

\author{
MIHAELA PAULA TOADER ${ }^{1 *}$, DANIEL CONSTANTIN BRANISTEANU ${ }^{2 *}$, \\ MIHAI GLOD $^{3}$, IRINA MIHAELA ESANU ${ }^{4}$, CATALINA IOANA BRANISTEANU ${ }^{5}$, \\ MARIA-STEFANA CAPSA ${ }^{6}$, ANDREEA DIMITRIU ${ }^{7}$, ALIN CODRUT NICOLESCU $^{8 *}$, \\ ALIN CONSTANTIN PINZARIU $^{9}$ and DACIANA ELENA BRANISTEANU ${ }^{10}$
}

Departments of ${ }^{1}$ Oral Dermatology, ${ }^{2}$ Ophthalmology, ${ }^{3}$ Surgery and ${ }^{4}$ Internal Medicine, 'Grigore T. Popa' University of Medicine and Pharmacy, 700115 Iasi; ${ }^{5}$ 'Grigore T. Popa' University of Medicine and Pharmacy, 700115 Iasi; ${ }^{6}$ Department of Dermatology, 'Railway Clinical Hospital', 700506 Iasi; ${ }^{7}$ Department of Dermatology, 'Arcadia' Hospitals and Medical Centers, 700620 Iasi; ${ }^{8}$ Department of Dermatology, Roma Medical Center for Diagnosis and Treatment, 011773 Bucharest; Departments of ${ }^{9}$ Physiology and ${ }^{10}$ Dermatology, 'Grigore T. Popa' University of Medicine and Pharmacy, 700115 Iasi, Romania

Received October 11, 2021; Accepted November 10, 2021

DOI: $10.3892 / \mathrm{etm} .2022 .11183$

\begin{abstract}
The ongoing COVID-19 pandemic, declared by the World Health Organisation in March 2020, with the emergence of new, possibly more contagious and more virulent strains, remains a research subject, with the complex systemic involvement better described and understood, but also with a variety of skin and mucosal lesions described in the literature. Mucocutaneous lesions associated with SARS-CoV-2 infection are still under investigation, due to their polymorphic clinical aspect and incompletely understood pathogenic mechanism. The cutaneous inflammatory, exanthematous and purpuric rashes, erythemato-purpuric enanthems, oral ulcers, lichenoid oral lesions, conjunctivitis, conjunctival pseudomembranes, or corneal lesions have been described in patients with COVID-19. Several classifications have been proposed based on the clinical pattern, histological findings, and possible pathogenic mechanisms. The pathogenic mechanism, the diagnostic criteria, the prognostic importance of these
\end{abstract}

Correspondence to: Dr Mihai Glod, Department of Surgery, 'Grigore T. Popa' University of Medicine and Pharmacy, 16 Universitatii Street, 700115 Iasi, Romania

E-mail: mihai_glod@yahoo.com

Dr Maria-Stefana Capsa, Department of Dermatology, 'Railway Clinical Hospital', 1 Garabet Ibraileanu Street, 700506 Iasi, Romania E-mail: stefana.capsa@yahoo.com

*Contributed equally

Key words: COVID-19, cutaneous manifestations, mucosal manifestations, exanthema, enanthem, purpura, urticarial rash, chilblain, conjunctivitis, livedo lesions are still being debated. The diverse clinical aspects of dermatological manifestations render the diagnosis difficult. However, several clinical patterns strongly associated with COVID-19, such as chilblains, papulovesicular exanthems, and febrile rash require increased awareness and changes to the investigation protocols for these conditions, to include testing for SARS-CoV-2. In the present review, the mucocutaneous findings associated with the novel coronavirus infection, reported thus far in the literature, was provided.

\section{Contents}

1. Introduction

2. Research methods

3. Prevalence

4. Pathogenesis

5. Classification and description of cutaneous, oral, and ocular mucosal lesions

6. Discussion and conclusions

\section{Introduction}

Despite the research data currently provided, cutaneous and mucosal manifestations of SARS-CoV-2 infection remain poorly known, particularly their prevalence, their morphological characteristics, the pathogenic substrate, as well as their diagnostic and prognostic significance. The ongoing pandemic, as well as the emergence of new viral strains, possibly more contagious and responsible for more severe disease (1), even with the development of several promising vaccines, that, however, have lower efficacy in a large group of individuals suffering from metabolic disorders, autoimmune diseases or with iatrogenic immune suppression (2), make it 
imperative to understand the complex clinical manifestations of COVID-19, including the signs and symptoms on the skin and mucous membranes. Case reports refer to a variety of morphological aspects that are either virus-induced or associated with antiviral therapy or secondary to the circumstances of the pandemic such as stress (herpes simplex, herpes zoster and alopecia areata) and environmental factors related to the use of antiseptics and disinfectants (contact dermatitis or urticaria) (3-8). According to a French study (conducted by Raymond-Poincaré University Hospital, Garches, France), which involved $\sim 40$ patients confirmed positive for COVID-19, the most common mucocutaneous manifestations were: macular exanthema (32 patients; trunk and head and neck were the areas preferentially involved, hand and feet were spared), face edema (13 patients), oral lichenoid reaction (13 patients), enanthema (11 patients), macroglossia (10 patients), cheilitis (5 patients), livedo reticularis (5 patients), urticarial rashes (3 patients), maculopapular exanthema (3 patients), purpura (2 patients), atopic dermatitis (1 patient), herpes (1 patient). All the patients presented extremely itchy lesions (9).

The positive diagnosis of skin and mucosal lesions in patients with COVID-19 is difficult and primarily requires the exclusion of drug-induced dermatoses $(10,11)$ and of other eruptions with similar clinical expression, particularly other viral infections. Cutaneous lesions in patients with SARS-CoV-2 infections are extremely variable in morphological patterns and their importance as a marker for the viral infection and for disease prognosis is still debated (6,12-15). Mucosal lesions are markedly less studied, but there are reports of oral mucous membrane changes and ocular conjunctival or corneal lesions in patients diagnosed with COVID-19, either as solitary findings or in association with cutaneous manifestations, with unclear pathogenic mechanisms, to date $(9,16,17)$.

A classification of the cutaneous lesions associated with SARS-CoV-2 infection based on the clinical aspect, pathogenic hypotheses, histopathological findings, associated disease severity, and prognostic importance, as well as a description of the most commonly encountered oral and ocular mucosal lesions during COVID-19 disease were reported in the present review.

\section{Research methods}

A literature search was conducted, using electronic databases Key Elsevier, Medscape, PubMed, Google Scholar, for the term 'COVID-19' in combination with 'skin', 'cutaneous manifestations', 'mucosal manifestations', 'rash', 'exanthem', 'enanthem', 'urticarial', 'chilblain', 'livedo', 'ocular mucosa', and 'purpura' to collect reports of skin and mucosal manifestations described in patients with COVID-19. Case reports, case series, and literature review-type articles were included in our research. A brief review was created, based on 63 articles identified in the literature.

\section{Prevalence}

Literature studies estimate a variable prevalence of the cutaneous and mucosal manifestations related to SARS-CoV-2 infection, between $0.2 \%$ (18), among Chinese patients, 15 out of 78 for Russian patients (3) and $20.4 \%$ in a study of 148 Italian patients (5).

\section{Pathogenesis}

The pathogenic mechanism is unclear. It may include the hyperactive immune response, the complement activation, and the microvascular injury. However, there are currently two proposed hypotheses, which classify the cutaneous manifestations of COVID-19 into two groups: i) manifestations linked to a direct cytopathogenic effect on cells such as keratinocytes, which are involved in numerous other viral infections (urticarial rashes, reactions similar to drug eruptions, varicella-like lesions) $(12,19)$; and ii) manifestations linked to an uncontrolled release of cytokines due to alterations involving specific white blood cells, such as T cells and macrophages. This second group could be divided into two other groups: a) manifestations similar to those in macrophage activation syndrome (acral ischemia, gangrene, retiform purpura, livedo racemosa) and b) cutaneous manifestations observed in young patients and linked to the activation of an early type I interferon (IFN) response (chilblain-like lesions) (20).

This hypothesis may provide a possible explanation of the pathophysiological mechanisms of the skin manifestations of COVID-19 disease.

\section{Classification and description of cutaneous, oral, and ocular mucosal lesions}

Several classifications have been proposed according to the morphological pattern and histological changes. The clinical patterns described include urticarial rash, confluent erythematous/maculopapular/morbilliform rash, papulosquamous rash, papulovesicular exanthem/varicella-like lesions, chilblains, livedo reticularis/racemosa-like pattern, purpuric 'vasculitic' pattern, vasculitides, livedo, and necrotic lesions (3,13,21-23).

Based on the morphological pattern, pathogenic hypotheses, and histological changes, the classification of skin manifestations was adapted into two main groups: i) inflammatory and exanthematous rashes (urticarial rash, maculopapular rashes, and papulovesicular rashes); and ii) vasculitic/vasculopathic lesions: acral ischemic lesions such as chilblain-like and acral ulcers, reticular purpuric lesions such as retiform purpura, livedo reticularis/livedo racemosa, and purpuric vasculitis, purpuric non-vasculitic lesions such as petechial rash and flexural and periflexural purpuric dermatitis. The lesions on the oral and ocular mucosa associated with SARS-CoV-2 infection are also presented.

\section{i) Inflammatory and exanthematous rashes}

a) Urticarial rash. The urticarial rash associated with COVID-19 has been reported in numerous publications. It was first mentioned by Recalcati in $16.7 \%$ of the total skin manifestations related to SARS-CoV-2 infection (5). Galván et al came to the conclusion that it occurs in $19 \%$ of cases, appears simultaneously with the systemic symptoms, lasts $\sim 1$ week, and is associated with medium-high severity of the infection. Pruritus may be identified in $92 \%$ of cases (21). The International League of Dermotological Societies (ILDS)/American Academy of Dermotology (AAD) registry, including over 1,000 patients reported a median duration of 4 days for urticarial rash (24). Freeman et al reported that urticarial lesions could be identified in $16 \%$ of the total cutaneous lesions, predominantly involve 


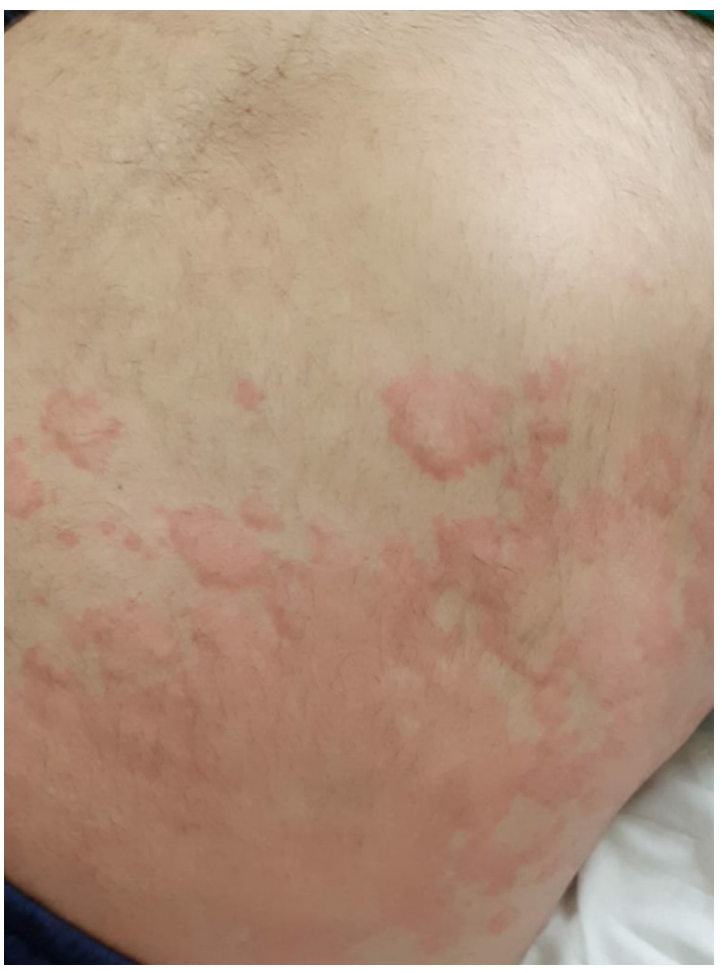

Figure 1. Urticarial rash consisting of eritemato-edematous pruritic, evanescent plaques on the trunk.

the trunk and the limbs, sparing the acral sites in most cases (Fig. 1) (24). The proposed pathogenic hypotheses include the unspecific activation of mast cells, direct endothelial damage [angiotensin-converting enzyme $2\left(\mathrm{ACE} 2^{+}\right)$], antigen-antibody deposits, complement activation, and kinin pathway activation. Whether the wheals are directly correlated with the novel coronavirus remains unclear, the etiopathogenic substrate being difficult to demonstrate, as urticaria may be drug-induced, particularly by antibiotics $(12,24,25)$. With the use of histopathology, Rodríguez-Jiménez et al identified a mild case of vacuolar interface dermatitis accompanied by few necrotic keratinocytes compatible with an erythema multiforme-like pattern (26). Amatore et al also reported the presence of lichenoid and vacuolar interface dermatitis, associated with mild spongiosis, dyskeratotic basal keratinocytes and superficial perivascular lymphocytic infiltrate in a patient diagnosed with COVID-19 who presented with erythemato-edematous non-pruritic annular plaques and fever (27).

b) Maculo-papular rashes. According to Galván et al, maculo-papular rashes are the most common skin manifestations in patients with COVID-19 (47\% of the cases) (21). They tend to occur concurrently or immediately following the other symptoms of the disease and are suggested to be associated with severe clinical forms, where the mortality may reach $2 \%$. Pruritus may be present in $56 \%$ of cases. The evolution is on average 8.6 days (21). Several subtypes have been described: morbilliform rash, erythema elevatum diutinum-like rash, erythema multiforme-like rash (typical target-like lesions mainly on the extremities, but also on the trunk, possibly induced by the virus), and digitiform papulosquamous rash $(9,21,23,28)$. Morbilliform rash presents

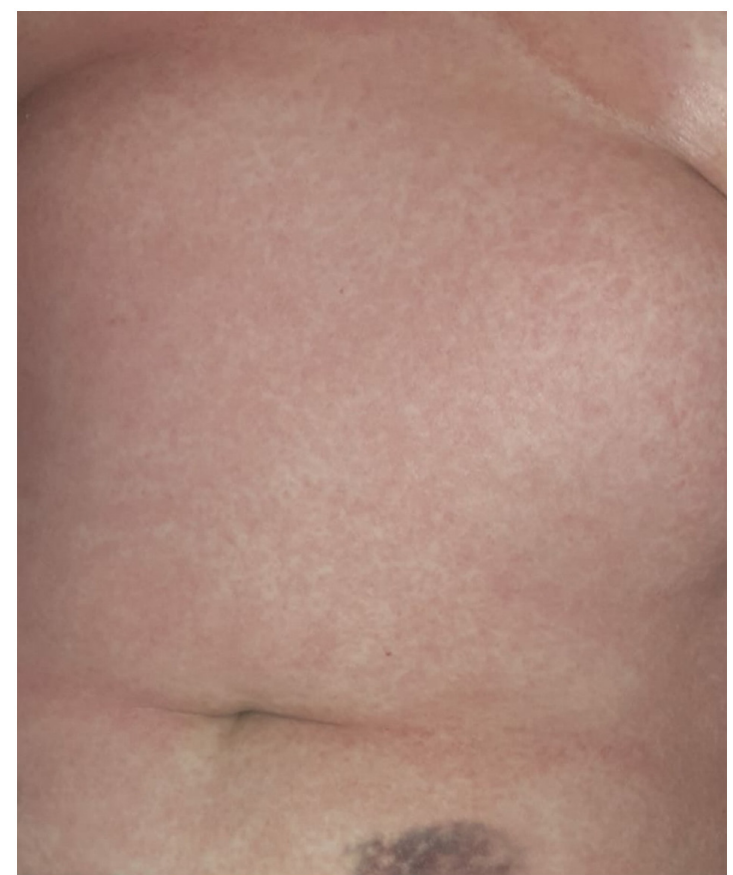

Figure 2. Morbiliform rash consisting of erythematous micro-papules and macules on the trunk.

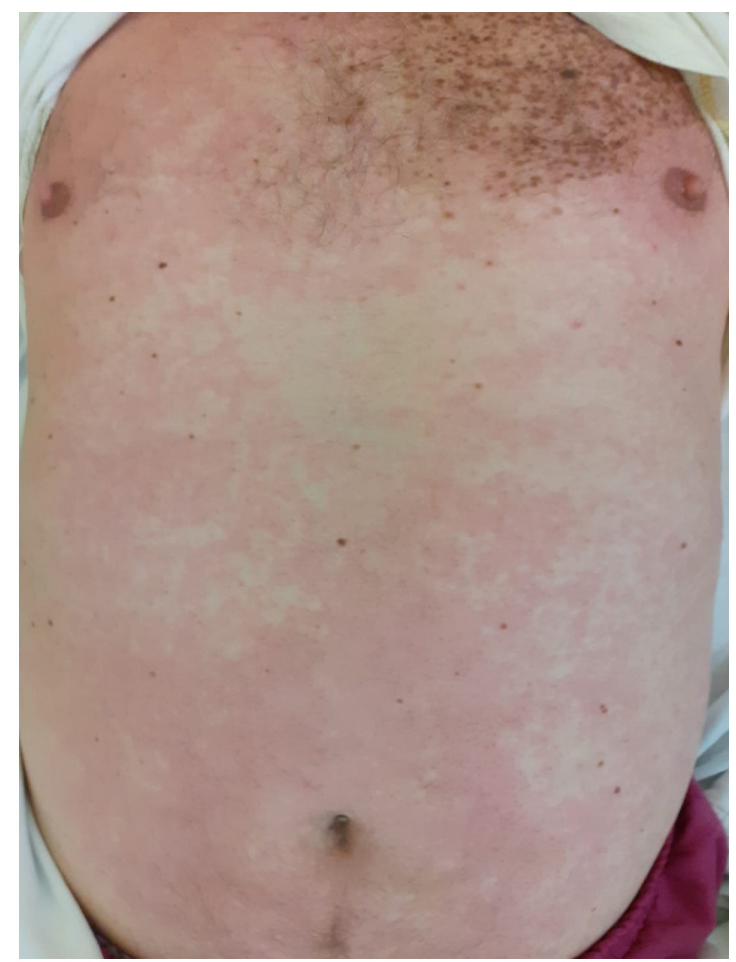

Figure 3. Erythematous macular rash on the trunk.

with maculo-papules or non-pruritic erythematous plaques, predominantly distributed on the trunk and extremities of the limbs excluding the face and the mucous membranes (Figs. 2 and 3). Onset is frequently following the onset of COVID-19 systemic symptoms. Differential diagnosis includes other viral exanthems and drug-induced cutaneous reactions $(21-23,28)$. Pityriasis rosea, including typical and 


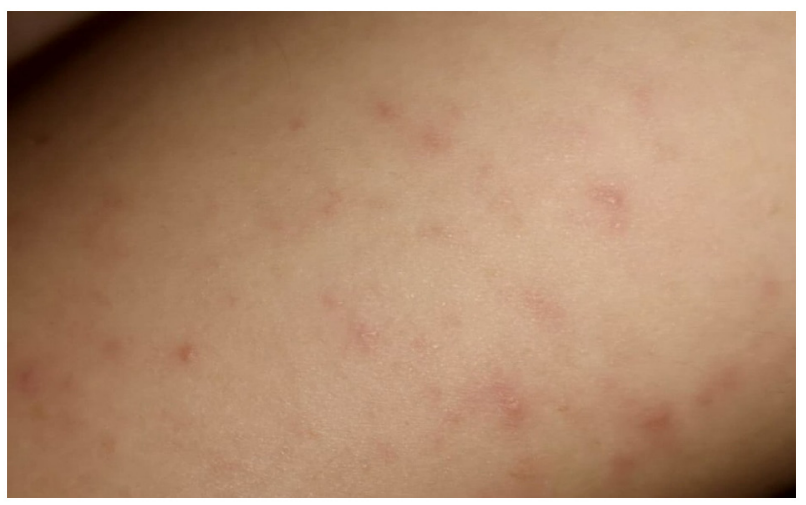

Figure 4. Papulo-vesicular rash.

atypical digitiform papulosquamous rash, has been described in association with SARS-CoV-2 infection, presumably as an expression of the immune response of the body to high levels of proinflammatory cytokines $(21,28,29)$. Histopathology of these erythematous eruptions, as described by Gianotti et al, revealed vascular damage in all the 3 cases examined (30). Reymundo et al observed a mild superficial perivascular lymphocytic infiltrate on the histology of 4 patients (31). By contrast, Herrero-Moyano et al observed neutrophilic infiltrate in 8 patients with late maculopapular eruptions. Collectively, the histopathology reveals changes similar to other viral rashes (32).

c) Papulovesicular exanthem/varicella-like lesions. Marzano et al revealed that the papulovesicular exanthems have a $9 \%$ prevalence, the median age is 60 years, but children may also be affected (33). In an unpublished study conducted in eight Italian dermatology units, skin lesions were reported to appear in most cases 3 days following the systemic symptoms and to disappear after 8 days, without scarring (13). The clinical aspect consists of a vesicular eruption similar to varicella (Fig. 4), or miliaria rubra-like disseminated lesions, located mainly on the torso $(13,33)$. Tammaro et al presented data from their combined experience in Rome (Italy) and Barcelona (Spain), and described similar lesions to ones identified in infections caused by members of the Herpesviridae family (34). Differential diagnosis must include herpetic infections and Grover's Disease (32). As a pathogenic hypothesis, direct viral damage to basal keratinocytes may be considered $(28,29,33,34)$. According to Mahé et al, histologically, these exanthems reveal acantholysis, intraepidermal vesicles with suprabasal clefts, prominent, 'pomegranate-like' dyskeratosis and suspected viral inclusions in multinucleated cells (35). Fernandez-Nieto et al identified another case of papulovesicular eruption which revealed extensive epidermal necrosis with acantholysis and swelling of keratinocytes, balloon degeneration of keratinocytes, and signs of endothelitis in the dermal vessels (36).

ii) Vasculitic/vasculopathic lesions associated with $S A R S-C o V-2$. The current hypotheses consider that the vasculitic/vasculopathic manifestations could be the result of small vessel occlusion, or it could be a neurogenic, microthrombotic, immune complex-mediated mechanism. A direct correlation with the SARS-CoV-2 virus has yet to be demonstrated $(37,38)$.

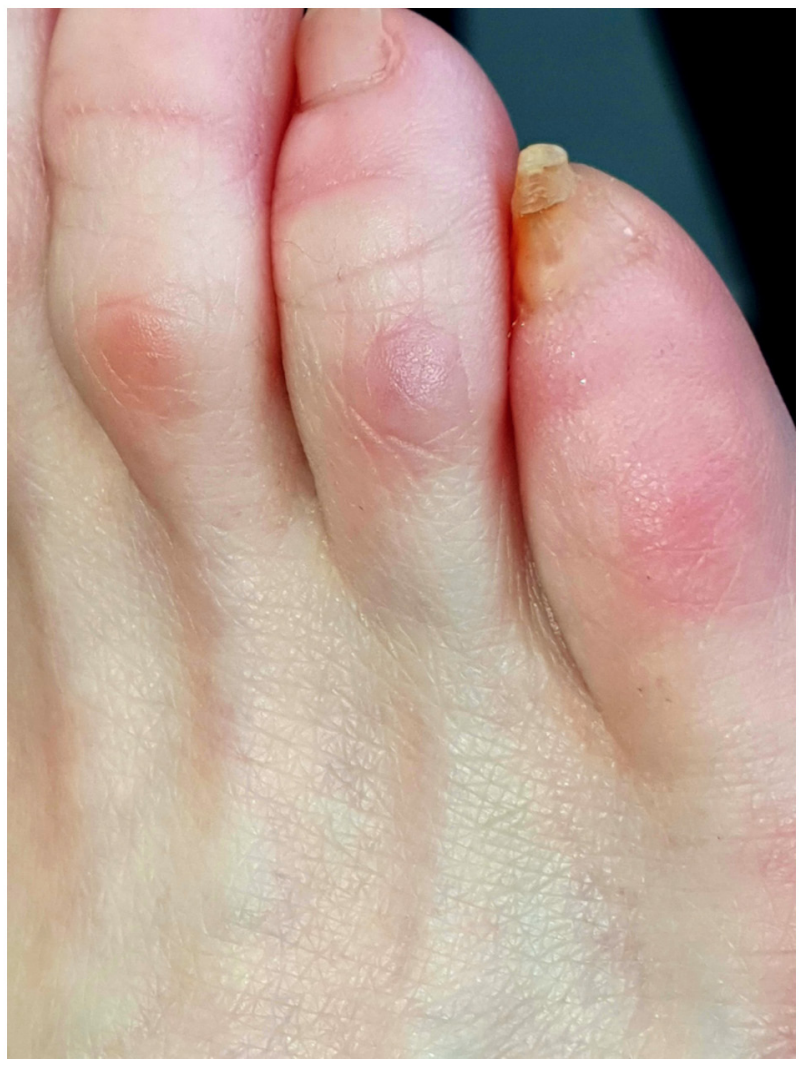

Figure 5. Chilblain-like lesions on the toes.

a) Ischemic acral lesions. Ischemic acral lesions were described in patients with COVID-19, presenting two types of clinical manifestations: chilblain-like/perniosis and acral ulcers. Chilblain-like lesions are painful cyanotic, red-purple macular or papular lesions, with acral disposition, particularly in the lower limbs (toes, but also plantar and calcaneal), accompanied by edema (Fig. 5) (21). These lesions occur mainly in children with asymptomatic clinical forms, in $19-40 \%$ of adults with less severe disease ( $16 \%$ hospitalized) and in females $(68 \%$ of cases), at younger ages (31.7 years on average). They appear later in the evolution of the COVID-19 disease, without cold exposure or other predisposing substrates, on average after the 9th day, but in certain cases, even following the recovery period $(3,7,11,19,20)$. The evolution is towards resolution in 2-8 weeks, with a duration of symptoms between 10 and 133 days, according to the ILDS/AAD registry (24). In patients with critical COVID-19 disease and disseminated intravascular coagulation severe manifestations with cyanosis of the toes, bullous lesions, and dry gangrene have been described $(22,23)$. The causal correlation between chilblain-like lesions and SARS-CoV-2 infection is still debated. French researchers did not identify chilblains predictive for COVID-19, as they investigated 40 patients suffering from chilblains, with the nasopharyngeal test (PCR) negative for all of these patients and positive serology in only one-third of them $(39,40)$. However, the increased occurrence of chilblain-like lesions during the COVID-19 pandemic, particularly in young patients with no history of predisposing factors, such as exposure to cold, as well as pathological reports of positive immunohistochemistry for SARS-CoV-2 from skin biopsies are arguments in favor 
of a COVID-19-associated type of chilblain $(10,41)$. The pathogenesis of SARS-CoV-2-associated chilblain involves vasospasm and microthrombosis through an increase in the vasoconstricting, prothrombotic and inflammatory pathway of angiotensin 2 induced by the viral cell infection, as well as acquired coagulopathy or endothelial cytotoxicity mediated by $\mathrm{CD}^{+} \mathrm{T}$ lymphocytes and robust interferon I (IFN-I) response $(20,22,37,41)$. Histological examination revealed lymphoid-lymphoplasmacytic infiltrate in the dermis possibly extending to the hypodermis and signs of endothelial activation or plump endothelial cells in the venules surrounded by infiltrate $(12,42)$.

An acral ulcer occurs in critically ill patients with COVID-19 with multiorgan involvement and manifests with purplish induration, livedoid plaques, bedsores. The pathogenic mechanism hypothesis focuses on the systemic coagulopathy leading to cutaneous ischemia (22).

b) Reticular purpuric lesions. Reticular purpuric lesions include retiform purpura, livedo reticularis and livedo racemosa. Retiform purpura is a severe manifestation that occurred in $82 \%$ of the hospitalized patients with acute respiratory distress syndrome. Its manifestations may include widespread purpura, hemorrhagic bullae, microthrombosis, progressive thrombocytopenia, with or without livedo racemosa (22).

Livedo reticularis/racemosa pattern. Livedo describes a condition of slow blood flow and blue cutaneous discoloration, which has been divided into 2 groups: livedo reticularis, generally associated with cold-induced cutaneous vasoconstriction and livedo racemosa, more frequently associated with focal impairment of blood flow such as Sneddon's syndrome. These lesions are described to appear any time during SARS-CoV-2 infection, mostly in older patients, localized on the limbs $(13,21,22)$. Livedo reticularis-like patterns are frequently mild, transient, unilateral, or bilateral and not associated with thromboembolic complications (43). On the contrary, livedo racemosa-like patterns have often been described in patients with severe coagulopathy $(13,21)$. Regarding the histopathology, Magro et al described pauci-inflammatory microthrombotic vasculopathy observed in three patients. They also demonstrated that in the racemosa-like pattern, in patients with a severe infection of COVID-19, the vascular thrombosis was associated with a minimal interferon response which increased viral replication and complement activation, probably involved in the pathophysiology of its clinical complications (41). Genovese et al distinguished the group of livedo reticularis/racemosa-like from the purpuric 'vasculitic' pattern since only the last one is considered the expression of a true vasculitis process (13).

Purpuric 'vasculitic' pattern. An Italian multicentric study revealed that this pattern is likely to be very rare representing $8.2 \%$ of skin manifestations (9). Joob and Wiwanitkit described the first purpuric lesion during the COVID-19 pandemic, as a petechial rash. Vasculitic lesions were described to appear more frequently in elderly patients with severe COVID-19, representing the cutaneous manifestations associated with the highest risk of death (44). The clinical appearance is that of

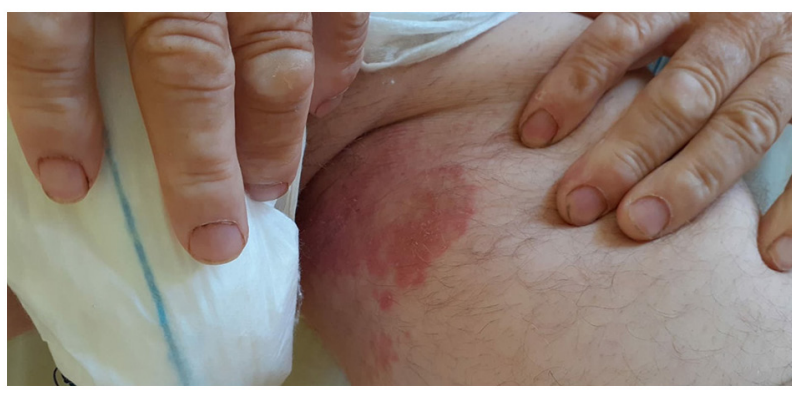

Figure 6. Purpuric flexural dermatitis.

palpable purpura, petechiae, hemorrhagic blisters, ulcers, with distribution on the lower limbs, or with purple and necrotic lesions similar to leukocytoclastic vasculitis. It occurs late during SARS-CoV-2 infection $(21,22)$. The pathogenic mechanism involves a complement-mediated inflammation caused by the immune complexes deposited in small vessels, with tissue destruction, associated with pro-coagulant status. Differential diagnosis includes drug-induced vasculitis $(20,22)$. A severe clinical form of vasculitis has been described, involving multisystem inflammatory syndrome in children who develop an exaggerated immune response to SARS-CoV-2 virus, with clinical manifestations similar to Kawasaki disease [acute vasculitis affecting children under 5 years of age and may lead to coronary aneurysms in $25 \%$ of untreated cases, triggered by an external factor, infectious agent, in individuals with genetic susceptibility (CASP3, HLA II, BLK, CD40)] (45-47). The mechanism of association of Kawasaki disease with viral infection is incompletely elucidated, but it is assumed that cytokines (IL-1, IL-6, IL-18) released by infected cells induce endothelial injury with vasculitic manifestations (47).

c) Purpuric non-vasculitic pattern. A petechial rash, probably secondary to thrombocytopenia, has been described, accompanied by macular/maculopapular lesions as a result of a non-vasculitic inflammatory process or as secondary lesions during the evolution of a maculopapular exanthem. Purpuric periflexural and flexural lesions (Fig. 6) have also been reported, with incompletely elucidated pathogenesis. These lesions were considered purpuric non-vasculitic since there was no histological evidence of a vasculitic inflammatory process $(21,22)$. Another dermatologic manifestation described in two patients in association with COVID-19 was the 'red half-moon nail sign', with no associated cutaneous lesions, that appeared between 2 and 14 days since the disease onset and persisted following the remission of respiratory symptoms $(48,49)$.

Oral mucosal lesions in patients with SARS-CoV-2 infection. Changes in oral mucous membranes in the context of SARS-CoV-2 disease have also been reported $(16,17)$. Petechial, macular and maculo-petechial enanthems were described in patients with COVID-19 disease, accompanied by a papulovesicular rash, periflexural purpura, and erythema-multiforme-like rash. These mucosal lesions occurring concurrently with a skin rash are indicative of a viral etiology, rendering the examination of the oral mucosa an important step in differentiating between drug-induced 
exanthems and viral-induced skin rashes in the context of the SARS-CoV-2 pandemic (16). Lingual pain was described in patients with COVID-19, possibly due to the higher expression of ACE2 receptor in the epithelial cells of the tongue (17). Oral ulcers, similar to recurrent herpes simplex or recurrent aphthous stomatitis have been reported by several authors. Pathogenic hypotheses focus on vascular and arterial thrombosis in small and medium-sized vessels $(16,17)$. Lichen-planus-like lesions have been reported in patients that had been diagnosed with COVID-19 in the previous 12 months $(16,17)$. In a Spanish study, $45.7 \%$ of 666 patients presented mucocutaneous lesions. On the oral mucosa, transient lingual papillitis was identified in $11.5 \%$ of cases, recurrent aphthous stomatitis in $6.9 \%$ of cases, glossitis with lateral indentations in $6.6 \%$ of cases, and depapilating glossitis in $3.9 \%$ of cases (16). The pathogenic mechanism for these manifestations is not yet fully understood.

Ocular mucosa lesions in patients with SARS-CoV-2 infection. The conjunctiva is considered to be an important part of the eye mucosa. It has a consistent barrier role against environmental and infectious agents due to numerous immunologic features common to other mucosal tissues $\left(\mathrm{CD}^{+}, \mathrm{CD}^{+} \mathrm{T}\right.$ cells, B cells, mast cells, dendritic cells, and Langerhans cells) $(50,51)$. The confirmation of both ACE2 (as the key entry receptor) and cellular serine protease TMPRSS2 expression on the ocular surface cells (52) makes the conjunctiva vulnerable for SARS-CoV-2 infection. In addition, the wide immunohistochemical detection of CD147 (promoter of viral invasion into the host cells), in different eye structures explains the viral propagation and enables ocular surface cells for further person-to-person transmission. The incidence of conjunctivitis in COVID-19 patients largely varies from $0.8 \%$ to $4.8 \%(18,53)$. A higher incidence $(\sim 3 \%)$ has been noted in severe COVID-19 cases as compared with only $0.7 \%$ in mild to moderate disease (54). The conjunctival signs, mostly bilateral, usually include mild to moderate hyperemia, follicular changes, chemosis, and discharge. A limited number of severe cases develop conjunctival pseudomembranes or corneal lesions (epithelial defects or subepithelial infiltrates) (55-57). The timing of conjunctivitis largely varies, certain patients reporting conjunctivitis-related symptoms (foreign body sensation, itching, and occasionally photophobia) before respiratory symptoms or fever. The possibility of contracting the SARS-CoV-2 infection via the eye is, at least in theory, plausible as the nasolacrimal duct may transport viral particles from the ocular surface to highly susceptible nasal epithelial cells from the inferior meatus (58). Other intriguing observations are that the detection of SARS-CoV-2 RNA in tears is not always associated with ocular manifestations as not every COVID-19 patient with conjunctivitis has a positive tear sample $(59,60)$.

\section{Discussion and conclusions}

Although millions of cases have been registered, no pathognomonic dermatological signs and symptoms for the disease have been identified yet. The polymorphic skin and mucosal lesions associated with SARS-CoV-2 infection are not an argument for the viral etiology, as usually, a certain virus is responsible for a single type of dermatologic manifestation. However, the increased incidence of the aforementioned clinical patterns of dermatologic conditions during the pandemic, suggests the association with the SARS-CoV-2 virus. The diverse clinical aspects may be explained by pathogenic differences between distinct strains of the virus, differences related to the host reactivity, and the possibility of co-infections. In contrast, skin and mucosal manifestations during COVID-19 may not only be related to the virus itself, but also to the viral-induced vasculitis and thrombotic vasculopathy, or they may be due to adverse reactions to the prescribed drugs $(6-8,61)$. The most common side effects associated with several of the often-prescribed drugs for COVID-19 infection (antimalarials) were maculopapular exanthematous reactions, urticaria, and psoriasis exacerbation. Oral antiretroviral combination lopinavir/ritonavir may be responsible for Stevens-Johnson syndrome (8). Temporal association between urticarial lesions and maculopapular eruptions with SARS-CoV-2 infection, when they appear concurrently as the systemic symptoms may be indicative of a viral etiology, rather than a drug-induced one (8). It is currently considered that two types of skin manifestations may be characteristic of the COVID-19 disease chilblain-like lesions and papulovesicular lesions. Therefore RT-PCR for SARS-CoV-2 (if the onset is less than 4 weeks previous) or serological testing (IgM, $\operatorname{IgG}$ ) for a potential SARS-CoV-2 infection should be added to the investigation protocol in patients without known risk factors who develop pernio-like lesions or in patients with papulovesicular rashes. Cases of COVID-19 with a clinical picture consisting of an infectious rash alone have been reported, making it imperative to investigate a febrile rash for the novel coronavirus as a possible cause $(30,61)$.

The description of the mucocutaneous manifestations associated with COVID-19 reviewed in this article may be helpful in the early recognition of cutaneous signs that are associated with severe complications (such as livedoid, necrotic or maculopapular lesions) and to establish prompt management essential in improving patients prognosis. Patients with autoimmune and chronic inflammatory disorders, such as psoriasis, atopic dermatitis, lupus, scleroderma, and hidradenitis suppurativa may require special care and adjustment of their immune-suppressive therapy protocol in order to maximize the chances for an effective response to anti-Covid-19 vaccines (2).

\section{Acknowledgements}

Not applicable.

\section{Funding}

Publishing fees were supported by the Association of Dermatologists of Moldova.

\section{Availability of data and materials}

Not applicable.

\section{Authors' contributions}

MPT and DEB contributed to the study design, participated in the entire review process, and prepared the manuscript. IME and CIB contributed to collecting the relevant literature, 
data analysis, and critical interpretation. MSC, MG, and DCB conceived the review and modified the manuscript. ACP, AD and ACN ensured that all questions related to the accuracy or integrity of the work are appropriately investigated and resolved. All authors read and approved the final version of the manuscript. Data authentication is not applicable.

\section{Ethics approval and consent to participate}

Not applicable.

\section{Patient consent for publication}

Not applicable.

\section{Competing interests}

The authors declare that they have no competing interests.

\section{References}

1. Docea AO, Tsatsakis A, Albulescu D, Cristea O, Zlatian O, Vinceti M, Moschos SA, Tsoukalas D, Goumenou M, Drakoulis N, et al: A new threat from an old enemy: Re-emergence of coronavirus (Review). Int J Mol Med 45: 1631-1643, 2020.

2. Calina D, Docea AO, Petrakis D, Egorov AM, Ishmukhametov AA, Gabibov AG, Shtilman MI, Kostoff R, Karvalho F, Vinceti M, et al: Towards effective COVID-19 vaccines: Updates, perspectives and challenges (Review). Int J Mol Med 46: 3-16, 2020.

3. Potekaev NN, Zhukova OV, Protsenko DN, Demina OM, Khlystova EA and Bogin V: Clinical characteristics of dermatologic manifestations of COVID-19 infection: Case series of 15 patients, review of literature, and proposed etiological classification. Int J Dermatol 59: 1000-1009, 2020.

4. Gisondi P, Piaserico S, Conti A and Naldi L: Dermatologists and SARS-CoV-2: The impact of the pandemic on daily practice. J Eur Acad Dermatol Venereol 34: 1196-1201, 2020.

5. Recalcati S: Cutaneous manifestations in COVID-19: A first perspective. J Eur Acad Dermatol Venereol 34: e212-e213, 2020 .

6. Ahouach B, Harent S, Ullmer A, Martres P, Bégon E, Blum L, Tess $\mathrm{O}$ and Bachmeyer $\mathrm{C}$ : Cutaneous lesions in a patient with COVID-19: Are they related? Br J Dermatol 183: e31, 2020.

7. Iordache AM, Docea AO, Buga AM, Mitrut R, Albulescu D, Zlatian O, Ianosi S, Ianosi G, Neagoe D, Sifaki M, et al: The incidence of skin lesions in contrast media-induced chemical hypersensitivity. Exp Ther Med 17: 1113-1124, 2019.

8. Martinez-Lopez A, Cuenca-Barrales C, Montero-Vilchez T, Molina-Leyva A and Arias-Santiago S: Review of adverse cutaneous reactions of pharmacologic interventions for COVID-19: A guide for the dermatologist. J Am Acad Dermatol 83: 1738-1748, 2020.

9. Mascitti H, Bonsang B, Dinh A, Assan F, Perronne V, Leblanc T, Duran C, Bouchand F, Matt M, Le Gal A, et al: Clinical cutaneous features of patients infected with SARS-CoV-2 hospitalized for pneumonia: A cross-sectional study. Open Forum Infect Dis 7: ofaa394, 2020.

10. Le Cleach L, Dousset L, Assier H, Fourati S, Barbarot S, Boulard C, Bourseau Quetier C, Cambon L, Cazanave C, Colin A, et al: Most chilblains observed during the COVID-19 outbreak occur in patients who are negative for COVID-19 on polymerase chain reaction and serology testing. Br J Dermatol 183: 866-874, 2020.

11. Brănișteanu DE, Ianoşi SL, Dimitriu A, Stoleriu G, Oanţă A and Brănișteanu DC: Drug-induced rowell syndrome, a rare and difficult to manage disease: A case report. Exp Ther Med 15 785-788, 2018

12. Kaya G, Kaya A and Saurat JH: Clinical and histopathological features and potential pathological mechanisms of skin lesions in COVID-19: Review of the literature. Dermatopathology (Basel) 7: 3-16, 2020.
13. Genovese G, Moltrasio C, Berti E and Marzano AV: Skin manifestations associated with COVID-19: Current knowledge and future perspectives. Dermatology 237: 1-12, 2021.

14. Darlenski R and Tsankov N: COVID-19 pandemic and the skin: What should dermatologists know? Clin Dermatol 38: 785-787, 2020.

15. Suchonwanit P, Leerunyakul K and Kositkuljorn C: Cutaneous manifestations in COVID-19: Lessons learned from current evidence. J Am Acad Dermatol 83: e57-e60, 2020.

16. Jimenez-Cauhe J, Ortega-Quijano D, de Perosanz-Lobo D, Burgos-Blasco P, Vañó-Galván S, Fernandez-Guarino M and Fernandez-Nieto D: Enanthem in patients with COVID-19 and skin rash. JAMA Dermatol 156: 1134-1136, 2020.

17. Rochefort J and Chaux AG: Oral mucosal lesions and Covid-19: Symptoms and/or complication? J Oral Med Oral Surg 27: 23 , 2021.

18. Guan W, Ni Z, Hu Y, Liang W, Ou C, He J, Liu L, Shan H, Lei C, Hui DSC, et al: Clinical characteristics of coronavirus disease 2019 in China. N Engl J Med 382: 1708-1720, 2020.

19. Aida Maranduca M, Liliana Hurjui L, Constantin Branisteanu D, Nicolae Serban D, Elena Branisteanu D, Dima N and Lacramioara Serban I: Skin-a vast organ with immunological function (Review). Exp Ther Med 20: 18-23, 2020.

20. Hubiche T, Cardot-Leccia N, Le Duff F, Seitz-Polski B, Giordana P, Chiaverini C, Giordanengo V, Gonfrier G, Raimondi V, Bausset $\mathrm{O}$, et al: Clinical, laboratory, and interferon-alpha response characteristics of patients with chilblain-like lesions during the COVID-19 pandemic. JAMA Dermatol 157: 202-206, 2021

21. Galván Casas C, Català A, Carretero Hernández G, Rodríguez-Jiménez P, Fernández-Nieto D, Rodríguez-Villa Lario A, Navarro Fernández I, Ruiz-Villaverde R, Falkenhain-López D, Llamas Velasco M, et al: Classification of the cutaneous manifestations of COVID-19: A rapid prospective nationwide consensus study in Spain with 375 cases. Br J Dermatol 183: 71-77, 2020.

22. Marzano AV, Cassano N, Genovese G, Moltrasio C and Vena GA: Cutaneous manifestations in patients with COVID-19: A preliminary review of an emerging issue. Br J Dermatol 183: 431-442, 2020

23. Gisondi P, PIaserico S, Bordin C, Alaibac M, Girolomoni G and Naldi L: Cutaneous manifestations of SARS-CoV-2 infection: A clinical update. J Eur Acad Dermatol Venereol 34: 2499-2504, 2020.

24. Freeman EE, McMahon DE, Lipoff JB, Rosenbach M, Kovarik C, Desai SR, Harp J, Takeshita J, French LE, Lim HW, et al: The spectrum of COVID-19-associated dermatologic manifestations: An international registry of 716 patients from 31 countries. J Am Acad Dermatol 83: 1118-1129, 2020

25. Seirafianpour F, Sodagar S, Pour Mohammad A, Panahi P, Mozafarpoor S, Almasi S and Goodarzi A: Cutaneous manifestations and considerations in COVID-19 pandemic: A systematic review. Dermatol Ther 33: e13986, 2020.

26. Rodríguez-Jiménez P, Chicharro P, De Argila D, Muñoz-Hernández $\mathrm{P}$ and Llamas-Velasco M: Urticaria-like lesions in COVID-19 patients are not really urticaria-a case with clinicopathological correlation. J Eur Acad Dermatol Venereol 34: e459-e460, 2020

27. Amatore F, Macagno N, Mailhe M, Demarez B, Gaudy-Marqueste C, Grob JJ, Raoult D, Brouqui P and Richard MA: SARS-CoV-2 infection presenting as a febrile rash. J Eur Acad Dermatol Venereol 34: e304-e306, 2020.

28. Tan SW, Tam YC and Oh CC: Skin manifestations of COVID-19: A worldwide review. JAAD Int 2: 119-133, 2021.

29. Usher AD: WHO launches crowdfund for COVID-19 response. Lancet 395: 1024, 2020

30. Gianotti R, Recalcati S, Fantini F, Riva C, Milani M, Dainese E and Boggio F: Histopathological study of a broad spectrum of skin dermatoses in patients affected or highly suspected of infection by COVID-19 in the Northern Part of Italy: Analysis of the many faces of the viral-induced skin diseases in previous and new reported cases. Am J Dermatopathol 42: 564-570, 2020.

31. Reymundo A, Fernáldez-Bernáldez A, Reolid A, Butrón B, Fernández-Rico P, Muñoz-Hernández P, De Argila D, Wiesner T and Llamas-Velasco M: Clinical and histological characterization of late appearance maculopapular eruptions in association with the coronavirus disease 2019. A case series of seven patients. J Eur Acad Dermatol Venereol 34: e755-e757, 2020 . 
32. Herrero-Moyano M, Capusan TM, Andreu-Barasoain M, Alcántara-González, Ruano-Del Salado M, Sánchez-Largo Uceda ME, Calzado-Villarreal L and Pérez-González Y: A clinicopathological study of eight patients with COVID-19 pneumonia and a late-onset exanthema. J Eur Acad Dermatol Venereol 34: e460-e464, 2020

33. Marzano AV, Genovese G, Fabbrocini G, Pigatto P, Monfrecola G, Piraccini BM, Veraldi S, Rubegni P, Cusini M, Caputo V, et al: Varicella-like exanthem as a specific COVID-19-associated skin manifestation: Multicenter case series of 22 patients. J Am Acad Dermatol 83: 280-285, 2020

34. Tammaro A, Adebanjo GAR, Parisella FR, Pezzuto A and Rello J: Cutaneous manifestations in COVID-19: The experiences of Barcelona and Rome. J Eur Acad Dermatol Venereol 34 e306-e307, 2020.

35. Mahé A, Birckel E, Merklen C, Lefèbvre P, Hannedouche C, Jost $\mathrm{M}$ and Droy-Dupré L: Histology of skin lesions establishes that the vesicular rash associated with COVID-19 is not 'varicella-like'. J Eur Acad Dermatol Venereol 34: e559-e561, 2020.

36. Fernandez-Nieto D, Ortega-Quijano D, Jimenez-Cauhe J, Burgos-Blasco P, de Perosanz-Lobo D, Suarez-Valle A, Cortes-Cuevas JL, Carretero I, Garcia-Del Real C and Fernandez-Guarino M: Clinical and histological characterization of vesicular COVID-19 rashes: A prospective study in a tertiary care hospitall. Clin Exp Dermatol 45: 872-875, 2020.

37. Cappel MA, Cappel JA and Wetter DA: Pernio (Chilblains), SARS-CoV-2, and COVID toes unified through cutaneous and systemic mechanisms. Mayo Clin Proc 96: 989-1005, 2021.

38. Hoenig LJ: Update on the cutaneous manifestations of COVID-19. Clin Dermatol 38: 507, 2020.

39. Bouaziz JD, Duong TA, Jachiet M, Velter C, Lestang P, Cassius C, Arsouze A, Domergue Than Trong E, Bagot M, Begon E, et al: Vascular skin symptoms in COVID-19: A French observational study. J Eur Acad Dermatol Venereol 34 e451-e452, 2020.

40. Guelimi R, Salle R, Dousset L, Assier H, Fourati S, Barbarot S, Boulard C, Bourseau Quetier C, Cambon L, Cazenave C, et al: Cutaneous manifestations during COVID-19 epidemic: COVID-skin study of the French society of dermatology. Ann Dermatol Venereol 147: A135, 2020. doi.org/10.1016/j. annder.2020.09.116.

41. Magro C, Mulvey JJ, Berlin D, Nuovo G, Salvatore S, Harp J, Baxter-Stoltzfus A and Laurence J: Complement associated microvascular injury and thrombosis in the pathogenesis of severe COVID-19 infection: A report of five cases. Trans Res 220: 1-13, 2020.

42. Alramthan A and Aldaraji W: Two cases of COVID-19 presenting with a clinical picture resembling chilblains: First report from the Middle East. Clin Exp Dermatol 45: 746-748, 2020.

43. Manalo IF, Smith MK, Cheeley J and Jacobs R: A dermatologic manifestation of COVID-19: Transient livedo reticularis. J Am Acad Dermatol 83: 700, 2020.

44. Joob B and Wiwanitkit V: COVID-19 can present with a rash and be mistaken for dengue. J Am Acad Dermatol 82: e177, 2020.

45. European Centre for Disease Prevention and Control: Paediatric inflammatory multisystem syndrome and SARS-CoV-2 infection in children - May 15, 2020. ECDC, Stockholm, 2020.

46. Verdoni L, Mazza A, Gervasoni A, Martelli L, Ruggeri M, Ciuffreda M, Bonanomi E and D'Antiga L: An outbreak of severe Kawasaki-like disease at the Italian epicentre of the SARS-CoV-2 epidemic: An observational cohort study. Lancet 395: 1771-1778, 2020.
47. Whittaker E, Bamford A, Kenny J, Kaforou M, Jones CE, Shah P, Ramnarayan P, Fraisse A, Miller O, Davis P, et al: Clinical characteristics of 58 children with a pediatric inflammatory multisystem syndrome temporally associated with SARS-CoV-2. JAMA 324: 259-269, 2020.

48. Méndez-Flores S, Zaladonis A and Valdes-Rodriguez R: COVID-19 and nail manifestation: Be on the lookout for the red half-moon nail sign. Int J Dermatol 59: 1414, 2020.

49. Neri I, Guglielmo A, Virdi A, Gaspari V, Starace M and Piraccini BM: The red half-moon nail sign: A novel manifestation of coronavirus infection. J Eur Acad Dermatol Venereol 34: e663-e665, 2020.

50. Sacks EH, Wieczorek R, Jakobiec FA and Knowles DM II: Lymphocytic subpopulations in the normal human conjunctiva. A monoclonal antibody study. Ophthalmology 93: 1276-1283, 1986.

51. Rodrigues MM, Rowden G, Hackett J and Bakos I: Langerhans cells in the normal conjunctiva and peripheral cornea of selected species. Invest Ophthalmol Vis Sci 21: 759-765, 1981.

52. Zhou L, Xu Z, Castiglione GM, Soiberman US, Eberhart CG and Duh EJ: ACE2 and TMPRSS2 are expressed on the human ocular surface, suggesting susceptibility to SARS-CoV-2 infection. Ocul Surf 18: 537-544, 2020.

53. Zhang X, Chen X, Chen L, Deng C, Zou X, Liu W, Yu H, Chen B and Sun X: The evidence of SARS-CoV-2 infection on ocular surface. Ocul Surf 18: 360-362, 2020.

54. Loffredo L, Pacella F, Pacella E, Tiscione G, Oliva A and Violi F: Conjunctivitis and COVID-19: A meta-analysis. J Med Virol 92: $1413-1414,2020$

55. Salducci M and La Torre G: COVID-19 emergency in the cruise's ship: A case report of conjunctivitis. Clin Ter 171: e189-e191, 2020.

56. Navel V, Chiambaretta $F$ and Dutheil F: Haemorrhagic conjunctivitis with pseudomembranous related to SARS-CoV-2. Am J Ophthalmol Case Rep 19: 100735, 2020.

57. Cheema M, Aghazadeh H, Nazarali S, Ting A, Hodges J, McFarlane A, Kanji JN, Zelyas N, Damji KF and Solarte C: Keratoconjunctivitis as the initial medical presentation of the novel coronavirus disease 2019 (COVID-19). Can J Ophthalmol 55: e125-e129, 2020.

58. Sungnak W, Huang N, Bécavin C, Berg M, Queen R, Litvinukova M, Talavera-López C, Maatz H, Reichart D, Sampaziotis F, et al: SARS-CoV-2 entry factors are highly expressed in nasal epithelial cells together with innate immune genes. Nat Med 26: 681-687, 2020.

59. Xia J, Tong J, Liu M, Shen Y and Guo D: Evaluation of coronavirus in tears and conjunctival secretions of patients with SARS-CoV-2 infection. J Med Virol 92: 589-594, 2020.

60. Wu P, Duan F, Luo C, Liu Q, Qu X, Liang L and Wu K: Characteristics of ocular findings of patients with coronavirus disease 2019 (COVID-19) in Hubei Province, China. JAMA Ophthalmol 138: 575-578, 2020.

61. Su CJ and Lee CH: Viral exanthem in COVID-19, a clinical enigma with biological significance. J Eur Acad Dermatol Venereol 34: e251-e252, 2020.

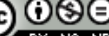

This work is licensed under a Creative Commons Attribution-NonCommercial-NoDerivatives 4.0 International (CC BY-NC-ND 4.0) License. 